\title{
Nutrition, Alcohol
}

National Cancer Institute

\section{Source}

National Cancer Institute. Nutrition, Alcohol. NCI Thesaurus. Code C15925.

Role of alcoholic beverages in cancer causation or prevention and in general health. 